\title{
Ground Plane Metamaterial Inspired Patch Antenna For L-Band Applications
}

\author{
Suyog VinayakPande, R. S. Kawitkar
}

\begin{abstract}
The patch antennas are very popular and useful antennas for small charge and solid design for RF uses and WiFi systems.

In Wi-Fi cellular phone call and satellite uses, patch antennas has magnetized a lot interest because of less dimension, cheap on mass production, less burden, short profile and simple incorporation with other parts. In this paper a new design of metamaterial technique is proposed with the patch antenna to modify its parameters. Antenna was designed at $1.9 \mathrm{GHz}$ and analyzed later to enhance its parameters and mainly bandwidth and Gain of the antenna, metamaterial was implemented. The coupling of patch and ground along with the metamaterial implementation on the ground plane made the bandwidth and Gain enhanced.
\end{abstract}

\section{Keywords -metamaterial, patch, bandwidth, Gain.}

\section{INTRODUCTION}

While designing airplane, missile and satellite, spacecraft etc. designing the dimension, mass, effortless installation, charge and aerodynamic outline are the limitations, and small shape radiators are generally needed. The MPA consistence too non-planar and planar ground, easy and economical to fabricate by current printed-circuit tools. The patch behaves like a transducer which contains resonant like cavity having its barriers like short circuit elements on front and back of the substrate. In a confined space or cavity there is only assured forms are permitted to be present, at unusual radiating frequencies. If frequency is applied to the radiator, a powerful ground is set up within cavity and a powerful current on the (base) ground of the patch. To conquer this difficulty without troubling their main benefit (for less burden and economical and instance plain structure of printed circuit,), numerous schemes and configurations have just been examined. Among the published research few authors published parasitic element [1], inclusion of metamaterial [3], feeding techniques [3], and DGS [4].

A single band micro-strip radiator which has photonic band gap structure (PBG) in the surface plane and also discussed the result of PBG to restrain the resonance of radiator at 17 harmonic frequencies was designed and simulated. The experimental study shows that radiation frequencies are drastically diminished when PBG structure is used. Third radiating frequency is repressed at more than $15 \mathrm{~dB}[13]$.

Revised Manuscript Received on 16 September, 2019.

SuyogVinayakPande, Department of Electronics and Telecomm Engg, Sinhgad College of Engineering, Vadgaon, Pune, India.Department of Electronics and Telecomm Engg, SVKM's NMIMS, Mukesh Patel School of Technology Manangement and Engineering, Shirpur Campus, Savalade, Maharashtra, India.

(Email: suyog2702@gmail.com)

R.S.Kawitkar, Department of Electronics and Telecommunication Engg, Sinhgad College of Engineering,Vadgaon, Pune, Maharashtra, India.

(Email: rskawitkar@rediffmail.com).
A double-polarized MPR which is able to attain a high isolation, small diffident radiation levels, broad bandwidth and small cross-polarization levels was fabricated.

The coupling aperture used is H-shaped. It uses stacked aperture coupled micro-strip square patches which is simple to add with active devices and gives wide bandwidth.

In this Dissertation return loss has bandwidth of $20.9 \%$ and over this bandwidth the isolation is enhanced than 36 dB. Front-to-back ratio and cross-polarization levels are also good [14].

A suggestion in which faulty ground structure is utilized in MPR which will restrain the upper level harmonics. An $\mathrm{H}$ shaped defect is cut in the surface plane which convert the radiation of the radiator in a far better radiation pattern. This proposed DGS radiating frequencies at harmonic frequencies correlate to MPR without DGS [8].

\section{CALCULATION}

At frequency of $1.9 \mathrm{GHz}$ a new antenna is proposed in this paper. Parameters were calculated by formulas listed in [5] and proposed antenna was designed using MWS tool of CST. Proposed rectangular antenna is shown in fig 1 and then in corresponding figures 2 and 3 simulation result were presented of the antenna designed at $1.9 \mathrm{GHz}$.

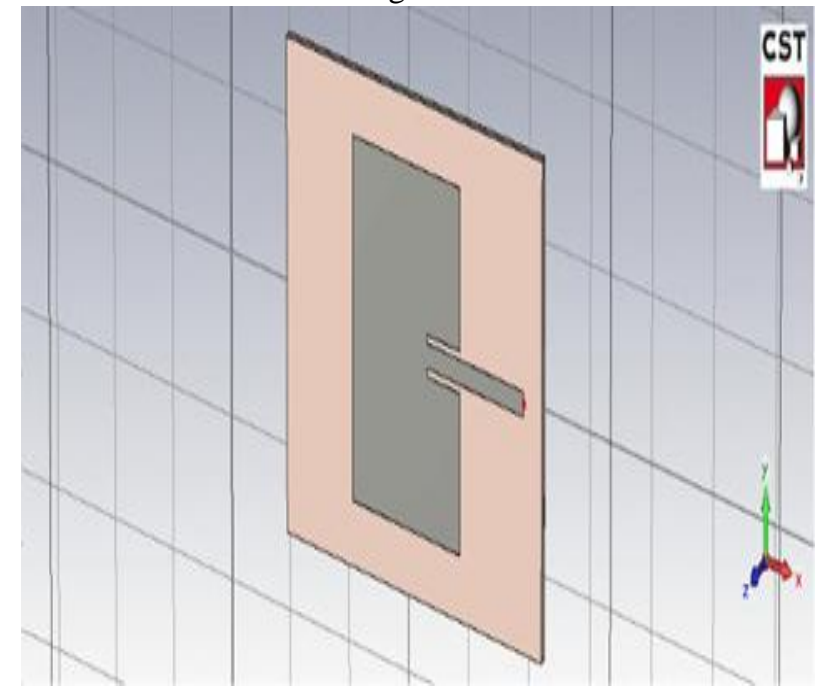

Fig. 1.Designed antenna at 1.9GHz frequency. 


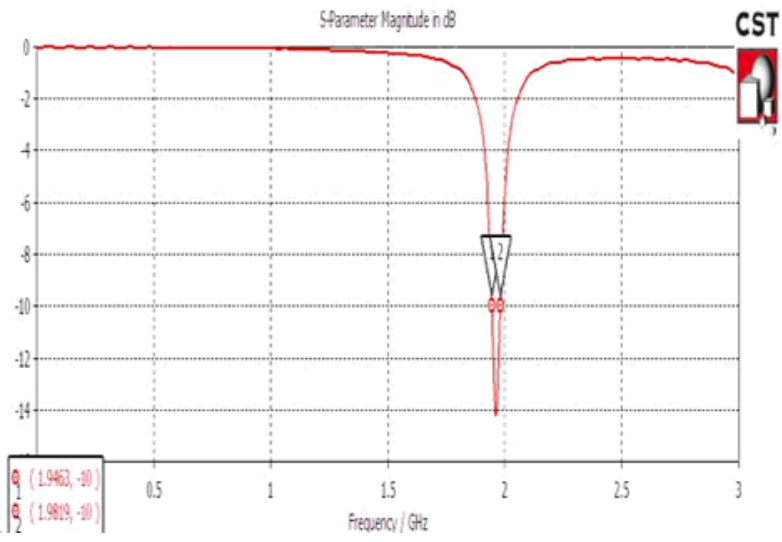

Fig. 2.Simulated result of patch showing return loss of $-14 \mathrm{~dB}$ at $1.9 \mathrm{GHz}$.

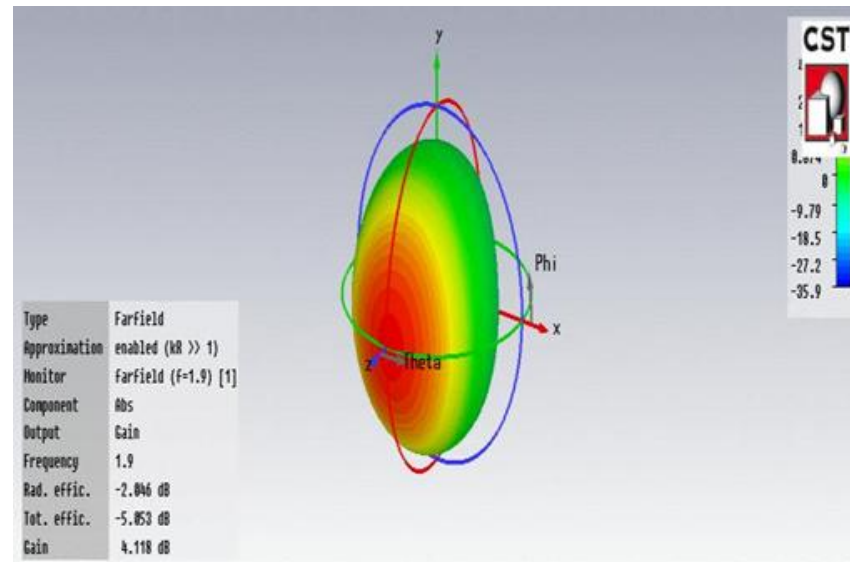

Fig. 3.Radiation pattern with Gain and Efficiency.

Designed RMPA was simulated and its result was presented above figures 2 and 3. It can be easily observed that proposed antenna having return loss of $-14 \mathrm{~dB}$ and bandwidth of $35 \mathrm{MHz}$. This antenna also having the gain of $4.118 \mathrm{dBi}$. These simulation results showing that antenna is not significantly applicable in any communication application. Which motivated authors to apply modification technique to improve the parameters of antenna. Following figure 4 represent the proposed metamaterial structure having a bar and a circular ring. The subsequent figures 5 and 6 represent the simulated results of after metamaterial introductions.

Fig. 4.Proposed metamaterial on the ground plane.
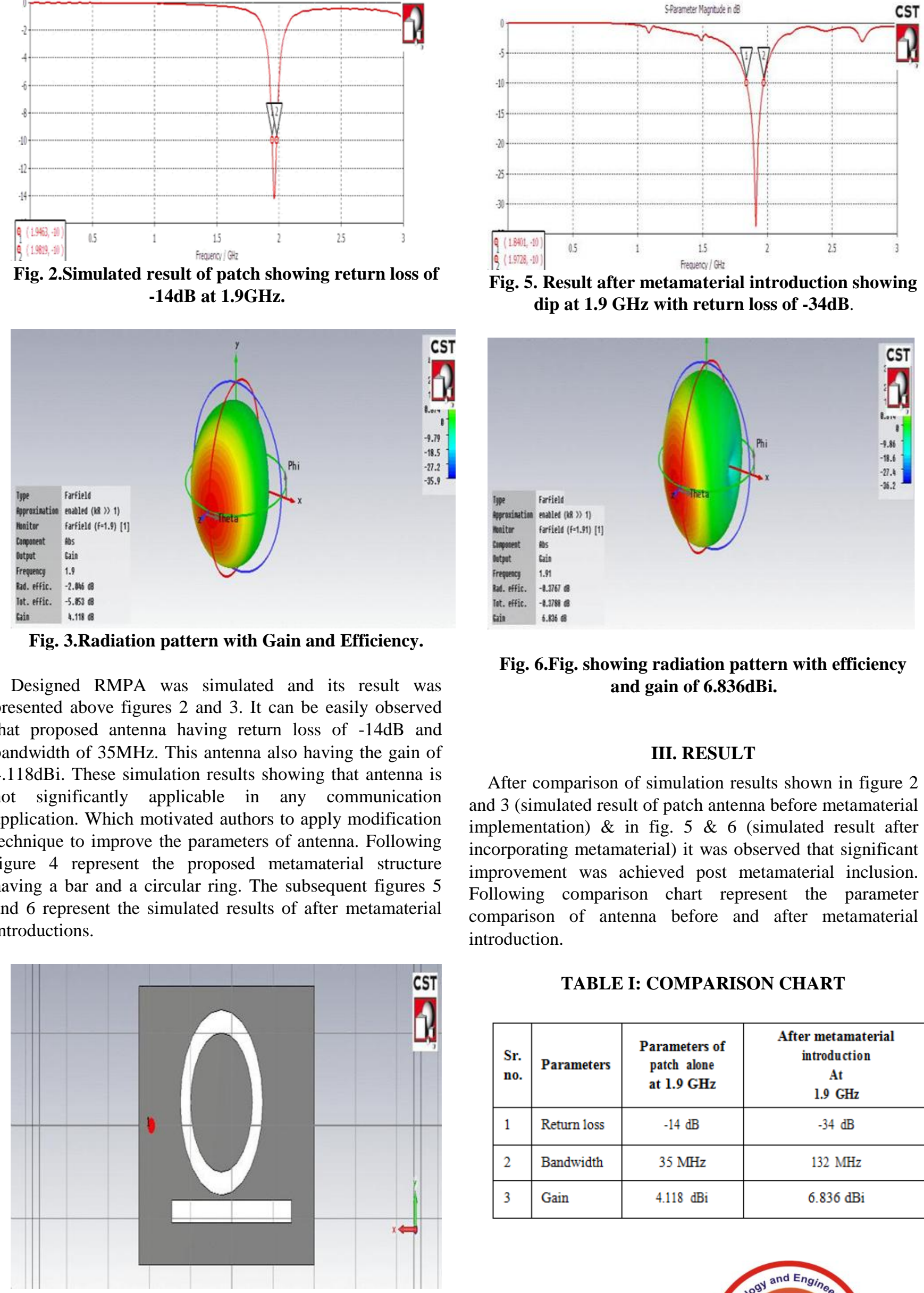

Fig. 5. Result after metamaterial introduction showing dip at $1.9 \mathrm{GHz}$ with return loss of $-34 \mathrm{~dB}$.

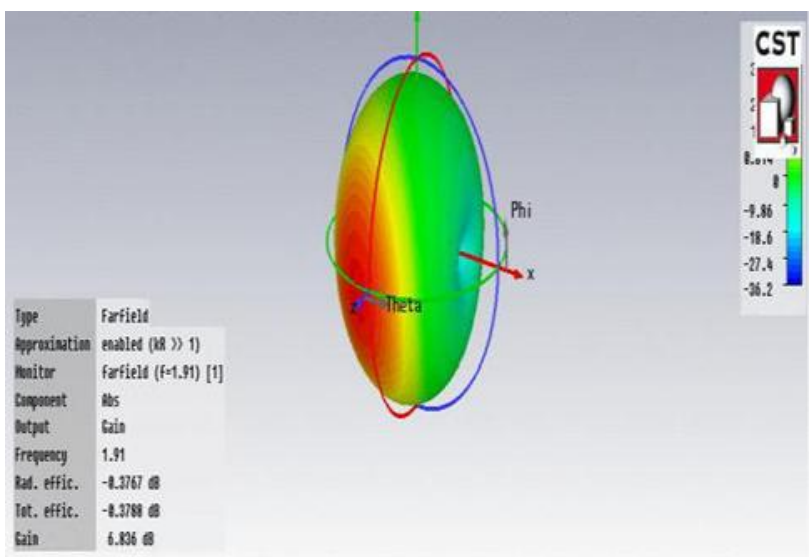

Fig. 6.Fig. showing radiation pattern with efficiency and gain of $6.836 \mathrm{dBi}$.

\section{RESULT}

After comparison of simulation results shown in figure 2 and 3 (simulated result of patch antenna before metamaterial implementation) \& in fig. $5 \& 6$ (simulated result after incorporating metamaterial) it was observed that significant improvement was achieved post metamaterial inclusion. Following comparison chart represent the parameter comparison of antenna before and after metamaterial introduction.

\section{TABLE I: COMPARISON CHART}

\begin{tabular}{|l|l|c|c|}
\hline $\begin{array}{c}\text { Sr. } \\
\text { no. }\end{array}$ & Parameters & $\begin{array}{c}\text { Parameters of } \\
\text { patch alone } \\
\text { at } 1.9 \mathrm{GHz}\end{array}$ & $\begin{array}{c}\text { After metamaterial } \\
\text { introduction } \\
\text { At } \\
1.9 \mathrm{GHz}\end{array}$ \\
\hline 1 & Return loss & $-14 \mathrm{~dB}$ & $-34 \mathrm{~dB}$ \\
\hline 2 & Bandwidth & $35 \mathrm{MHz}$ & $132 \mathrm{MHz}$ \\
\hline 3 & Gain & $4.118 \mathrm{dBi}$ & $6.836 \mathrm{dBi}$ \\
\hline
\end{tabular}


From the comparison table, it can be easily analyzed that post metamaterial introduction the improvement of antenna parameters was achieved. This improvement not only made the antenna applicable in desired applications but it became directive as well. Return loss improved just double times andbandwidth improved 4 times the value of antenna alone, gain of the antenna increased as well.

\section{CONCLUSION}

Proposed antenna is designed for $\mathrm{L}$ band applications. Formerly alone patch antenna was showing insignificant results, later metamaterial was incorporated to improve the antenna characteristics. A ring and bar shaped metamaterial structure was implemented in the ground plane of the proposed antenna, inclusion of this metamaterial structure improved the characteristics to significant level. Bandwidth and gain both simultaneously shown a significant improvement as well as efficiency was also improved. Modified patch can be used in L band applications like WLAN and Satellite applications. $400 \%$ change in bandwidth and around $50 \%$ change in gain has been achieved post metamaterial inclusion.

\section{REFERENCES}

1. Jun-Won Kim, Tae-Hwan Jung, Hong-KyunRyu, Jong-Myung Woo, "Compact Multiband Microstrip Antenna Using Inverted L and TShaped Parasitic Elements." IEEE Antennas and Wireless Propagation Letters, vol. 12, 2013, pp. 1299-1302.

2. Emad S. Ahmed "Multiband CPW-Fed Rectangular Ring Microstrip Antenna Design for Wireless Communications." IEEE Jordan Conference, AEECT, 2011.

3. D. M. Pozar, "Introduction to microwave system" in Microwave Engineering, 4th Edition. John Wiley \& Sons 2004, pp. 658-99.

4. PradeepPaswan, Vivekanand Mishra, P. N. Patel, SurabhiDwivedi " Performance Enhancement of Coaxial Feed Microstrip Patch Antenna Using Left-Handed Metamaterial Cover," IEEE conference, SCEECS, 2014.

5. RajeshwarLalDua, Himanshu Singh, NehaGambhir "2.45 GHz Microstrip Patch Antenna with Defected Ground Structure for Bluetooth", IJSCE, Volume-1, Issue-6, January 2012, pp. 262265

6. C. A. Balanis, "Microstrip Antenna" in Antenna Theory and Design, Vol 3, John Wiley \& Sons, Inc., 1997, pp. 811-882.

7. S. Park et al., "An internal triple-band planner inverted $\mathrm{F}$ antenna", IEEE Antennas and wireless propagation letters, Vol. 2, 2003.

8. Lin, Shun?Yun, and Kin?Lu Wong. "Effects of slotted and photonic bandgap ground planes on the characteristics of an air?substrateannular?ring patch antenna in the TM21 mode." Microwave and Optical Technology Letters 31, no. 1 (2001): 1-3.

9. Y.J. Sung, M. Kin,and Y.S. Kin, "Harmonics Reduction with Defected Ground Structure for Micro-strip Patch Radiator" ,IEEE Radiator and Wireless Propagation Letters, Vol. 2, 2003.

10. Beaky, Matthew M., John B. Burk, Henry O. Everitt, Mansoor A. Haider, and StephanosVenakides. "Two dimensional photonic crystal Fabry-Perot resonators with lossy dielectrics." Microwave Theory and Techniques, IEEE Transactions on 47, no. 11 (1999): 2085-2091

11. R.P.S. Bhadoriya and S. Nigam, "Bandwidth enhancement and modification of single band patch antenna into double band," 3rd Intrernational conference on Computing for Sustainable Global Development, New Delhi, Vol 2, pp. 1029-1032, 2016

12. D. R. Jackson and N. G. Alex6poulos, "Gain enhancement methods for printed circuit antennas," IEEE Trans, Antennas Propag, vol. AP33, no. 9, Sep, 1985.

13. H. Nakano, M. Ikeda, K. Hitosugi, and 1. Yamauchi, "A spiral antenna sandwiched by dielectric layers," IEEE Trans. Antennas Propag., vo1.52, no. 6, Jun. 2004,

14. Y. Horri and M. Tsutsumi, "Harmonic control by photonic bandgap on micro-strip patch radiator," IEEE Microwave Guided Letters, Vol 9, pp. 13-15, Jan. 1999.

15. S.C. Gao, L.W. Li, P. Gardner and P.S. Hall, "Wideband dualpolarized micro-strip patch radiator," Vol. 37, No. 20,pp-1213 1214,August 2001. 